\title{
Gaze correlates of view preference: comparing natural and urban scenes
}

\author{
A Batool M.Arch , $\mathbf{P}$ Rutherford $\mathrm{PhD}^{\mathrm{a}}, \mathbf{P}$ McGraw $\mathrm{PhD}^{\mathrm{b}}$, T Ledgeway $\mathrm{PhD}^{\mathrm{b}}$ and $\mathbf{S}$ \\ Altomonte $\mathrm{PhD}^{\mathrm{c}}$ \\ ${ }^{\text {a }}$ Faculty of Engineering, University of Nottingham, Nottingham, UK \\ ${ }^{\mathrm{b}}$ School of Psychology, University of Nottingham, Nottingham, UK \\ ${ }^{\mathrm{c}}$ Faculty of Architecture, Architectural Engineering, Urbanism (LOCI), Université Catholique \\ de Louvain, Louvain-la-Neuve, Belgium
}

Short Title: Gaze correlates of view preference

Received 25 May 2021; Revised: 22 August 2021; Accepted: 7 October 2021

When looking out of a window, natural views are usually associated with restorative qualities and are given a higher preference than urban scenes. Previous research has shown that gaze behaviour might differ based on the natural or urban content of views. A lower number of fixations has been associated with the aesthetic evaluation of natural scenes while, when looking at an urban environment, a high preference has been correlated with more exploratory gaze behaviours. To characterise gaze correlates of view preference across natural and urban scenes, we collected and analysed experimental data featuring subjective preference ratings, eye-tracking measures, verbal reasoning associated with preference, and nature relatedness scores. Consistent with the literature, our results confirm that natural scenes are more preferred than urban views and that gaze behaviours depend on view type and preference. Observing natural scenes was characterised by lower numbers of fixations and saccades, and longer fixation durations, compared to urban views. However, for both view types, most preferred scenes led to more fixations and saccades. Our findings also showed that nature relatedness may be correlated with visual exploration of scenes. Individual preferences and personality attributes, therefore, should be accounted for in studies on view preference and gaze behaviour.

Address for correspondence: Ayesha Batool, Human Factors Research Group, Faculty of Engineering, University of Nottingham, Nottingham NG7 2RD, UK

Email: ayesha.batool@nottingham.ac.uk 


\section{Introduction}

With people spending increasingly more time within buildings, ${ }^{11}$ windows are often valued for the view and connections they afford to the outside. ${ }^{22}$ Natural views are usually given a higher preference rating than views with urban features, ${ }^{3}$ and greater interest in window views has been found to positively influence visual ${ }^{4,5}$ and thermal perception. ${ }^{6}$ Research has explored the factors that contribute to human preferences for natural views. ${ }^{7}$ Some studies have suggested that, from an evolutionary perspective, humans have a predisposition to prefer landscape features through "genetic inheritance"., 8 This plays a central role in the biophilia hypothesis ${ }^{10}$ and in theories such as the prospect-refuge, ${ }^{11}$ savannah (habitat), ${ }^{12}$ information processing, ${ }^{13}$ attention restoration (ART),${ }^{14}$ and stress reduction $(\mathrm{SRT}){ }^{15}$. Nevertheless, empirical evidence supporting the contribution of such evolutionary influences on the aesthetic evaluation of natural scenes remains sparse and needs to be better substantiated ${ }^{16}$.

Higher preferences for natural over urban views are thought to be mediated by perceptions of greater restorative potential in natural environments. ${ }^{13,17-21}$ However, scenes rated as highly restorative are not necessarily those that are more preferred. ${ }^{22}$ In fact, restoration might not always predict environmental preference. ${ }^{23}$ Some studies have found human predisposition for natural views to be detached from aesthetic preference for outdoor scenes, and varying across age groups ${ }^{24}$ and cultures. ${ }^{25}$ Differences in individuals, such as their reported connection to nature, may also be attributed to differences in perceived restorative potential of scenes. ${ }^{21}$

Physiological measures such as the dynamics of gaze can provide valuable insights into a person's attention, awareness, and information processing behaviour. ${ }^{26-28}$ Eye position and eye movements can be accurately tracked and reliably measured using a range of techniques that are briefly described below. Several studies have demonstrated a link between the characteristics of the scene and the gaze behaviour of the observer. ${ }^{29-31}$ Given the growing 
interest towards the potential benefits of outdoor views, it is important to consider the potential interrelations between their physiological, psychological, and aesthetic features. ${ }^{32}$ In fact, many of the findings from the literature related to preferred landscape features ${ }^{13}$ cannot be directly replicated, or transferred to other contexts (e.g., urban views), due to their use of subjective assessment protocols. ${ }^{33}$ Therefore, beyond subjective ratings, ${ }^{34}$ a more holistic and objective approach is required to reach reliable and robust measures of view preference.

To characterise gaze correlates of view preference across natural and urban scenes, in this paper we first analyse three types of experimental data on natural views: subjective preference ratings, qualitative reasoning, and eye-tracking measures captured during scene viewing. We then compare the data with those collected in a previous experiment, in which we investigated gaze characteristics associated with view preference while the same participants looked at urban scenes. ${ }^{35}$ Finally, differences in gaze behaviour associated with urban and natural views are further examined in the context of participants' reported attitude towards nature, as measured by their nature relatedness score (NRS). ${ }^{36}$

Eye-tracking measures (ETMs) have long been used as signature for cognitive attention, ${ }^{37}$ not just to identify where observers are looking, ${ }^{38}$ but as correlates of attention allocation and cognitive load. This relationship has led researchers interested in the restorative effects of nature to track eye movements. In fact, different scenes - natural and urban - might engage viewers through distinct types of directed attention and fascination.

In an eye-tracking study, ${ }^{29}$ eye movements related to urban scenes were characterised by higher exploration, as indicated by a greater number of fixations and larger saccade amplitudes (eye travel distance), when compared to those for natural scenes. These results were replicated by Valtchanov and Ellard ${ }^{39}$ and then by Franek et al., ${ }^{40}$ who also included comparisons with urban scenes featuring historical buildings. In the literature, longer fixation durations have been found when scenes are perceived as natural. ${ }^{35,41}$ Night-time cityscapes 
have shown a positive correlation between ETMs (fixation duration and scan path length) and preference. ${ }^{42}$ These findings are, however, not consistent with other studies that have measured view interest while considering view type. Using ETMs, Kaspar \& König ${ }^{43}$ found that participants who rated an image as interesting showed significantly shorter fixation durations and higher number of saccades. Accounting for image type, they found shortest durations and highest frequency (number of fixations) for urban scenes. Other studies have shown that high-level aspects of a scene, as captured by interest, are highly efficient in guiding eye movements and that the competition to scan other image regions of interest might lead to reduced fixation durations. ${ }^{44}$ Similarly, Batool et al. ${ }^{35}$ found that highly preferred urban views were associated with greater visual exploration, with higher numbers of fixations and saccades. However, these gaze characteristics reversed when urban scenes were perceived as featuring natural contents, with a lower number of fixations compared to other preferred urban views. This led to the hypothesis, tested in the current paper, that gaze behaviour might be driven by view type and preferences toward urban or natural environments. ${ }^{35}$ Further studies using ETMs have shown that building occupants attend to the window component of their field of view during breaks, allowing analysis of the factors of a view out that attract attention. ${ }^{38,45}$ Eye-tracking measures, therefore, afford the opportunity to objectively investigate how space is visually experienced beyond the known trends in view preference.

\section{Method}

\subsection{View preference for natural images}

This study is based on the systematic replication of the experimental protocol we used to investigate view preference in urban environments. ${ }^{35}$ The selection of participants, the experimental apparatus, and the test procedure were deliberately kept the same as the previous study to allow a robust comparison of data using a within-subjects experimental design. 


\subsubsection{Participants}

Participants who had participated in our previous study ${ }^{35}$ were contacted 6 months after the first recruitment and were given the opportunity to take part in a new experiment. Fifteen people (out of 32 contacted) volunteered to the new study. Participants $\left(n_{p}=15\right)$ were all University staff and research students. Seven participants identified themselves as female. They all reported normal or corrected-to-normal vision and no previous history of neuropsychological disorders. Participants were told that the purpose of the experiment was to replicate the previous study with a new set of stimuli to test the reliability of the findings. Participation involved informed consent for the data to be collected and analysed in line with the study's granted ethical approval.

\subsubsection{Visual stimuli}

A set of 40 images $\left(n_{v}=40\right)$ of natural scenes were acquired from the open access McGill Calibrated Colour Image Database. ${ }^{46}$ A variety of natural views were selected to offer a wide range of scene depth, greenness, water content, and human presence (see Supplementary Material, Table A1.1).for the whole image sample along with stimuli IDs in the database).

\subsubsection{Experimental apparatus and procedure}

The experimental procedure, lasting 60 minutes and taking place during normal office hours, required participants to look at the images of natural scenes, provide ratings of preference (preference rating task) while their eye movements were tracked, and verbal reasoning for their evaluations (pile sorting task). Participants were also asked to fill an instrument (nature relatedness score) to measure their personal relationship with nature.

The preference rating task involved the presentation of each image for 15 seconds, ${ }^{29-}$ ${ }^{31)}$ while monocular eye movements were recorded using an EyeLink 1000 infrared eye 
tracker (SR Research Ltd, Ontario, Canada). Since the task that an observer is performing is known to affect their gaze behaviour, ${ }^{26,27}$ participants were asked to observe each image as if it were a real view and to give a rating of view preference, this being defined as "how much you like the scene for whatever reason you may have". The preference evaluation was rated on a visual analogue scale, anchored at the two ends by the descriptors 'most preferred' and 'least preferred'. The images were presented on the full screen of a pre-calibrated 22" CRT monitor (Iiyama Vision Master Pro 514; resolution 1024*768 pixels, background luminance $45 \mathrm{~cd} / \mathrm{m}^{2}$ ) using the PsychoPy 2.0 software package. ${ }^{47}$ The participant sat at a distance of $0.655 \mathrm{~m}$ from the monitor, with their head secured using a chin and headrest. The 40 images were linearly re-scaled to $1024 * 768$ pixels and split into 4 blocks, each containing 10 images. The order of image presentation within each block was randomised. A balanced Latin Square design ${ }^{48}$ determined the sequence of blocks and participants were offered a break between each block to reduce fatigue. Each block started with a nine-point calibration procedure, to enable the conversion of the eye tracking raw data into gaze coordinates. Each participant viewed and rated each image once, completing one practice block followed by four experimental blocks. Only data from the experimental blocks were retained for analysis.

A pile sorting task was included in the experimental procedure to identify and analyse characteristic features of views that could moderate subjective preferences. Using the same 40 images printed on matt photographic cards $\left(10.16^{*} 15.24 \mathrm{~cm}\right)$, participants were asked to observe the images from a randomly ordered pile, select their three most and three least preferred views, and provide verbal reasoning for their choices. Explanations for the selection and categorisation of views were recorded and transcribed.

The Nature Relatedness Scale (NRS) is a self-reported measure of the affective, cognitive, and experiential aspects of an individual's relation with nature (36). Items in the scale are based on three sub-themes (See Supplementary Material, Table A3.1). The first sub- 
theme, 'self', is a representation of one's internalized identification with nature, e.g. 'My relationship to nature is important to who I am'. The second theme, 'perspective', is an external reflection of one's nature-related worldview, e.g. 'I feel very connected to all living things and the Earth.' The third sub-theme, 'experience', is based on familiarity with the physical natural world based on prior experience, e.g. 'My ideal vacation spot would be a remote, wilderness area.' Participants filled out their responses, with each element evaluated using a 5-point Likert scale.

\subsubsection{Data analysis}

Data gathered from each participant were assigned a corresponding Participant ID (115). All preferences were associated with an image ID (i1-i40). Data from subjective ratings and eye-tracking measures were organised in a $15 * 40$ (participant*image) matrix using SPSS Statistics version 25.0 (SPSS, Chicago, IL). Since all dependent variables were measured at a continuous level, means across data were used for subsequent analysis.

MATLAB $2017 \mathrm{a}^{49}$ was used to analyse ETMs data. In order to present unbiased interpretation of gaze metrics, ${ }^{28,50}$ an open-source software package for event detection ${ }^{51}$ was adopted to derive eye movement statistics from three eye tracking measures: number of fixations, number of saccades, and mean fixation duration. Heat maps (HMs) were created by weighting the total number of fixations with time and superimposing them on the images in MATLAB.

To compare differences in ETMs based on view preference, the mean-split method was used to undertake two types of data analysis. In the first, the preference ratings for all images and all participants were combined to derive a grand-mean for the entire group. This grand-mean was used as a benchmark to divide the sample into two categories: 'most preferred' and 'least preferred' views. Subjective preference ratings and ETMs (number of fixations, number of saccades, and mean fixation duration), identified for each image ID, were 
systematically tested to confirm whether they met the conditions for parametric analysis. ${ }^{52}$ When ETMs violated the assumptions required for parametric tests, non-parametric MannWhitney tests were used. Otherwise, independent samples t-tests were run to compare the differences in gaze between least and most preferred views for number of fixations, number of saccades, and mean fixation duration. Inferences were based on the estimation of the statistical significance ( $p$-value at the alpha level of 0.05 ) and the magnitude of effect size, using the Cohen- $d$ coefficient based on established benchmarks (respectively, 0.2, 0.5, and 0.8 for small, medium, and large effects). ${ }^{53}$

In the second analysis, the mean preference across all views was calculated separately for each participant and used as a threshold to sort 'most preferred' and 'least preferred' views. This analysis considered individual differences in view preference and enabled us to compare ETMs for the views that were most and least preferred by each participant. A difference score was calculated for each ETM and tested for normality. Shapiro-Wilk tests confirmed normal distributions of data for number of fixations $(p=0.062)$, number of saccades $(p=0.066)$ and mean fixation duration $(p=0.890)$, and boxplots did not show any outliers. Within-subject differences in ETMs were tested using (related) t-tests. To estimate the magnitude of the differences detected for each ETM between most preferred and least preferred natural views, the $r$ coefficient was calculated. ${ }^{52,54}$ Inferences were based on the detection of statistical significance ( $p$-value) and on estimation of effect sizes $(r)$ based on established benchmarks (with 0.1, 0.3 and 0.5 marking, respectively, small, moderate and strong effects $\left.{ }^{53}\right)$

Selections of the three most and the three least preferred natural views given by each of the 15 participants were tabulated. Verbal reasoning data for both most and least preferred views were coded in the NVivo-12 Pro (QSR International) qualitative data analysis software. Using the Word Frequency Query feature in NVivo 12 Pro, lists were generated featuring the 
words and the descriptors that participants most frequently used to refer to the scenes they had selected as their least and most preferred.

\subsection{Comparison between natural and urban views}

All 15 participants had in a previous experiment designed to evaluate preferences within urban views. ${ }^{35}$ In this study, using the same experimental protocol, participants were exposed to a different set of visual stimuli - natural scenes - in order to identify any withinsubject difference in preferences and gaze behaviour between urban and natural views. To conduct the within-subject analysis, data gathered from the 15 participants were extracted from the previous study, ${ }^{35}$ and a $15 * 40$ matrix for each dependent variable was created.

All dependent variables were measured on a continuous scale. For each dependent variable, two conditions were identified: urban and natural. In this way, data were matched for each participant via participant ID and imported into SPSS Statistics 25.

For each pair of variables, a difference score statistic was generated. The distribution of each difference statistic was inspected for normality and for outliers. The difference scores between natural and urban views were normally distributed, as assessed by Shapiro-Wilk's tests for number of fixations $(p=0.723)$, number of saccades $(p=0.779)$, and mean fixation duration $(p=0.551)$. Boxplots were used for detecting outliers. Boxplots are a standardized way of displaying the distribution of data based on a six number summary ("minimum", i.e. Q1 - 1.5*IQR, first quartile (Q1), median, the InterQuartile Range (IQR), third quartile (Q3), and "maximum", i.e. Q3 + 1.5*IQR). No data points were found beyond the minimum and maximum values. As the assumptions of normality were met, within-subject (related) t-tests were used for comparing the ETMs associated with the urban and natural views.

Similar to natural views (Section 2.1.4), the ETMs data for urban scenes were reevaluated using each participant's preference ratings to split views into 'most preferred' and 
'least preferred' categories. Difference scores for each ETM were populated and inspected for normality and outliers. Shapiro-Wilk tests confirmed normal distributions for number of fixations $(p=0.370)$, number of saccades $(p=0.926)$, and mean fixation duration $(p=0.125)$. Visual inspection of boxplots did not show any outliers. Within-subject (related) t-tests were then run on the urban views data. Inferences were based on the estimation of statistical significance ( $p$ value) and magnitude of effect size $(r)$.

In addition, the relationship between the reported NRS scores in each viewing condition - i.e., for urban $\left(\mathrm{NRS}_{\text {urban }}\right)$ and natural $\left(\mathrm{NRS}_{\text {natural }}\right)$ scenes - and gaze behaviour was analysed. NRS scores ranged from 0 to 5 . The NRS scores were collated to calculate a sum score for each participant. ${ }^{36}$ In order to analyse relationships between ETMs and NRS, a Pearson's product-moment correlation analysis was run with the NRS score as an independent variable. Estimation of the Pearson $r$ coefficient was based on the previously mentioned benchmarks. $^{53}$

\section{Results}

\subsection{Natural views}

\subsubsection{Preference rating}

Table 1 presents the mean and standard deviation of the subjective preference ratings given by participants for the 40 images (i1-i40). For photographs of views please refer to the Supplementary Material, Table A1.1). Results from the Shapiro-Wilk test and visual inspection of histograms and Q-Q plots confirmed that, across all images, preference rating data were normally distributed with a skewness of $-0.647(S E=0.374)$ and kurtosis of -0.198 $(S E=0.733)$.

A test for internal consistency was performed to evaluate the reliability of the preference ratings. ${ }^{52}$ To do this, measurements were randomly split into two halves and the 
mean preference rating across the 40 images was calculated for each half sample. The two sets of 40 mean-per-setting scores were inter-correlated for preference using a SpearmanBrown reliability test. This resulted in a test coefficient of 0.786 , suggesting acceptable reliability, ${ }^{55,56}$ and a Cronbach's alpha of $0.852 .{ }^{52}$

A comparison was made between the most and least preferred views given in the preference rating and in the pile sorting tasks (individual selections of views for each participant are listed in the Supplementary Material, Table A2.1). These two tasks produced consistent results, with views i4, i33, and i6 being the three most frequently preferred views (Table 2). Similarly, views i5, i35, and i27 were the three least preferred images in both tasks. Figure 1 shows these most frequently selected 'most preferred' and 'least preferred' natural views and their associated heatmaps (HMs). HMs, also known as attention maps, allow visualising the distribution of gaze points, using colours to indicate the time spent on different locations. $^{28}$

Figure 1 Most frequently selected (A) 'most preferred' and (B) 'least preferred' natural views and their heatmaps. Normalised fixation frequency is the total number of times that a pixel was viewed in the image, divided by the total number of valid eye-tracker samples for the duration of the image presentation, $15 \mathrm{~s}$ (after removing blinds).

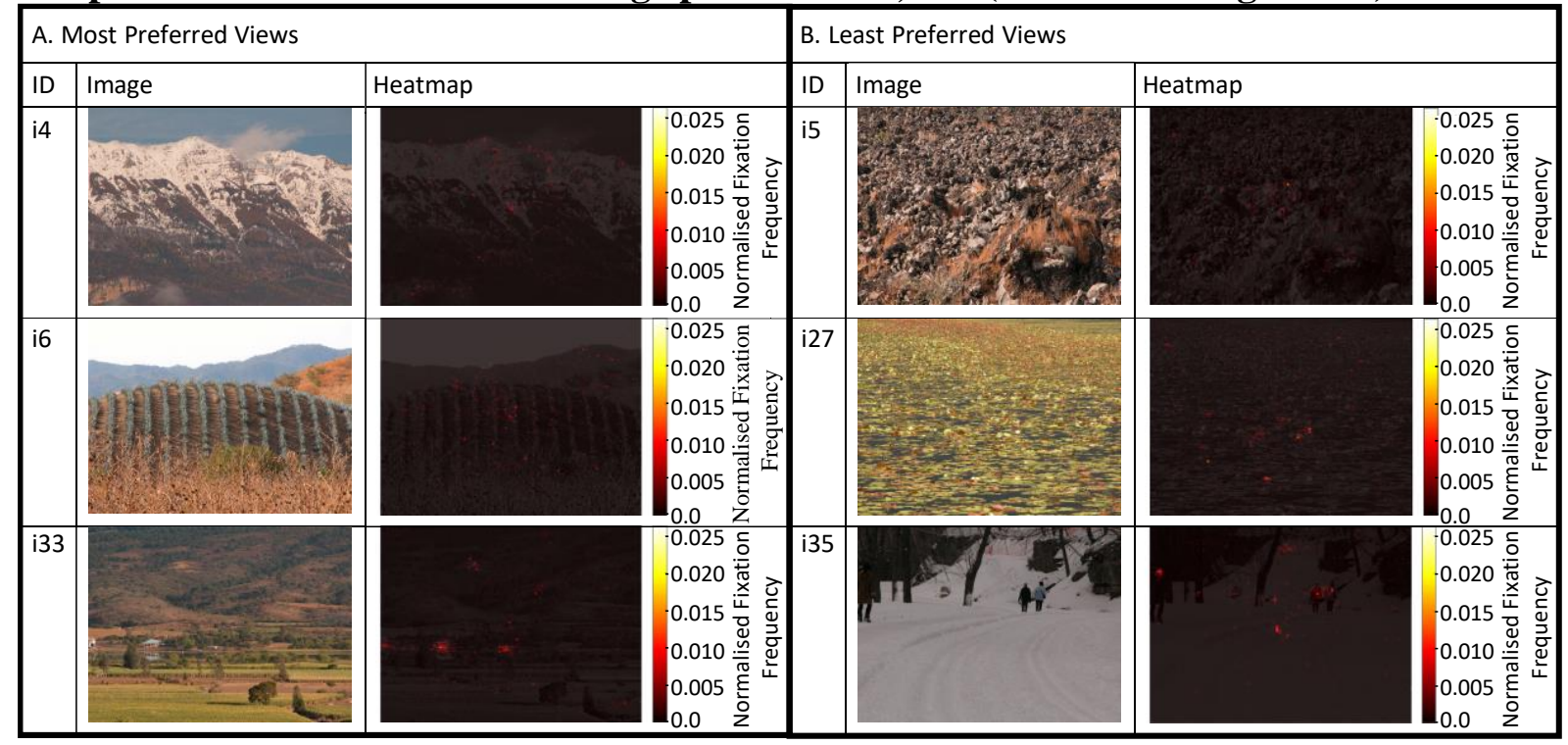

Note: For better interpretation of the heatmaps colour scales, the reader is referred to the online version of this article. 


\subsubsection{Gaze behaviour characteristics}

To test whether view preference was associated with a particular pattern of oculomotor response, least preferred and most preferred natural views were analysed using eye-tracking measures (ETMs) to test for significant and practically relevant differences in gaze behaviour between views.

Using the grand-mean-split on preference rating, an independent sample t-test was conducted as the data fulfilled the conditions for parametric tests. The test did not find statistically significant differences in the number of fixations between least and most preferred views $(\mathrm{t}(38)=1.300, p=0.133)$, although an effect size bordering practical relevance was detected $(d=0.202)$. Similarly, no statistically significant differences were found between most and least preferred view in number of saccades $(\mathrm{t}(38)=1.162, p=0.252)$, but a small effect size was detected $(d=0.368)$. Differences in mean fixation durations were also not significant $(\mathrm{t}(38)=0.065, p=0.948, d=0.021)$. Therefore, for the oculomotor responses considered, the grand-mean (group) split method did not lead to detect any significant differences in gaze behaviour between most or least preferred natural views.

A within-subject (related) t-test was then used to determine whether statistically significant differences between ETMs could be detected based on individual participants' preference ratings $\left(n_{p}=15\right)$ when observing their own 'most preferred' and 'least preferred' natural views $\left(\mathrm{n}_{\mathrm{v}}=40\right)$ (Figure 2$)$. Data are mean \pm standard deviation, unless otherwise stated. In the most preferred view category, participants' gaze was characterised by a significantly higher number of fixations $(26.820 \pm 6.342)$ compared to the least preferred $(25.802 \pm 5.728)$ natural views $(\mathrm{t}(14)=4.334, p=0.001, r=0.757)$ (Figure $2(\mathrm{a}))$. Similarly, the number of saccades was significantly higher for most preferred $(38.049 \pm 6.020)$ than for least preferred $(36.953 \pm 5.312)$ natural views $(\mathrm{t}(14)=2.871, p=0.012, r=0.609)$ (Figure 2(b)). Finally, a tendency was found for mean fixation durations to be higher for least 
preferred $(0.390 \pm 0.053 \mathrm{~s})$ than most preferred $(0.377 \pm 0.045 \mathrm{~s})$ natural views; this difference failed to reach statistical significance but a practically relevant size of effect was detected $(\mathrm{t}(14)=2.001, p=0.065, r=0.472)($ Figure $2(\mathrm{c}))$.
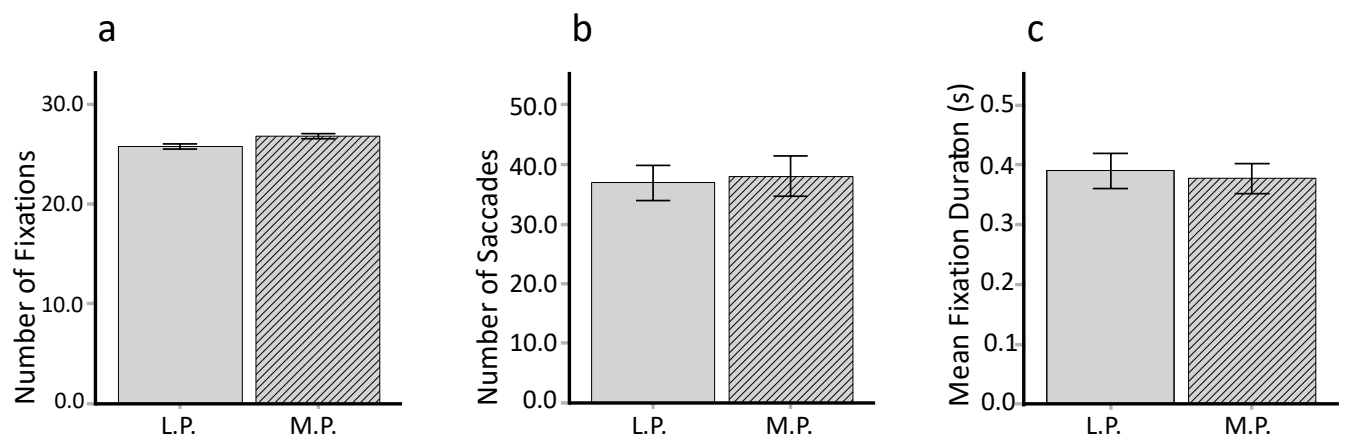

Figure 2 Gaze behaviour measures for most preferred and least preferred natural views, for all participants $\left(n_{p}=15\right)$ and all views in the sample $\left(n_{v}=40\right) . a=$ Number of fixations, $b=$ Number of saccades, $c=$ Mean Fixation Duration. $L P=$ Least Preferred Views, MP = Most Preferred Views. Error Bars represent +/- 2 SE.

\subsubsection{Word descriptors of view preference}

Analysis of the verbal reasoning data revealed that the most and the least preferred natural views were associated with generic words illustrating the features or the attributes of the scenes (Table 3).

Participants mentioned the words colour, mountain or hill, people or human, and sky, and these were more frequent in most preferred views. The natural features and presence of a tree and water were also mentioned in both categories.

The word people was mentioned often as a gateway to perceiving activities, e.g., participants stated that having people "around you [...] indicates this is a place you can go and there's life there", etc. Even when people were not actually visible in the scene, human intervention was observed as a reassuring presence, e.g., "although there are no people in it, it 
has signs of human activity”. Conversely, in least preferred views, human presence was associated with visibly difficult or threatening environments, e.g.: "people inside the picture are struggling to climb".

The word colour was often used to refer to landscape features in most preferred views, the "colour represents harmony between sand and water", chromatic qualities, "vibrant colour" and, composition in the scene, e.g., "very nice mix of colours". In least preferred views, negative connotations of colour were mentioned as "no particularly nice colour either", "the colour doesn't look nice", or "mundane colour, bland".

In most preferred views, participants noticed the patterns in the sky and just being able to "see the sky" was mentioned as a reason for preference. For example, a scene was preferred when described as "what you would see when you lie down on grass and looking up on sky through trees." In contrast, "boring, featureless sky" was also noted. Participants who liked "being close to water" and preferred the "seaside and clear water" recalled previous "nice memories of seaside", mentioning water in most preferred views. However, when the body of water was not considered clean, and "not taken care of", its presence in the scene was not preferred. The presence of a tree was often mentioned. Some participants mentioned the "changing colours" of leaves in most preferred views and "no leaves on trees" in least preferred views. Similarly, emphasis on natural characteristics was frequent. Views with distant landscapes including a mountain or hill were highly favoured and, therefore, they were mentioned more often in the most preferred category.

The descriptors used to explain preference of views in the two categories allowed us to explore the reasons for view selection. Table 4 lists the most commonly recurring descriptors used to illustrate most and least preferred views.

The most preferred views were described as "peaceful" and reminiscent of "holiday" destinations. Some views reminded the participants of "home", while others were 
representative of "changing" colours and seasons. In contrast, the least preferred views were perceived as "difficult" landscapes that were "inhospitable", "barren", not supporting life and where participants "can't" navigate through the space or see much further.

\subsection{Comparison between natural and urban views}

The data collected in this experiment were compared to those gathered in our previous study (35) to measure any difference in subjective preference ratings and ETMs across two view type conditions: natural and urban scenes. All descriptive summary statistics are provided below as mean \pm standard deviation, unless otherwise stated.

\subsubsection{Subjective preference ratings}

A paired-sample t-test was used to determine whether there was any statistically significant ( $p$-value) and practically relevant (effect size) difference between the preference ratings for natural and urban views for the same 15 participants. There were no outliers in the data, as assessed by boxplot inspection for values greater than 1.5 box-lengths from the edge of the box. The assumption of normality was not violated, as assessed by Shapiro-Wilk's test $(p=0.252)$. Participants' subjective preference ratings were significantly higher for natural $(0.598 \pm 0.071)$ than urban views $(0.448 \pm 0.096)$, with a practically relevant effect size $(\mathrm{t}(14)=5.618, p<0.0001, d=1.450$ (large effect)). Figure 3 presents the distribution of preference ratings between participants, across the two view type categories (error bars show $95 \%$ confidence intervals). 


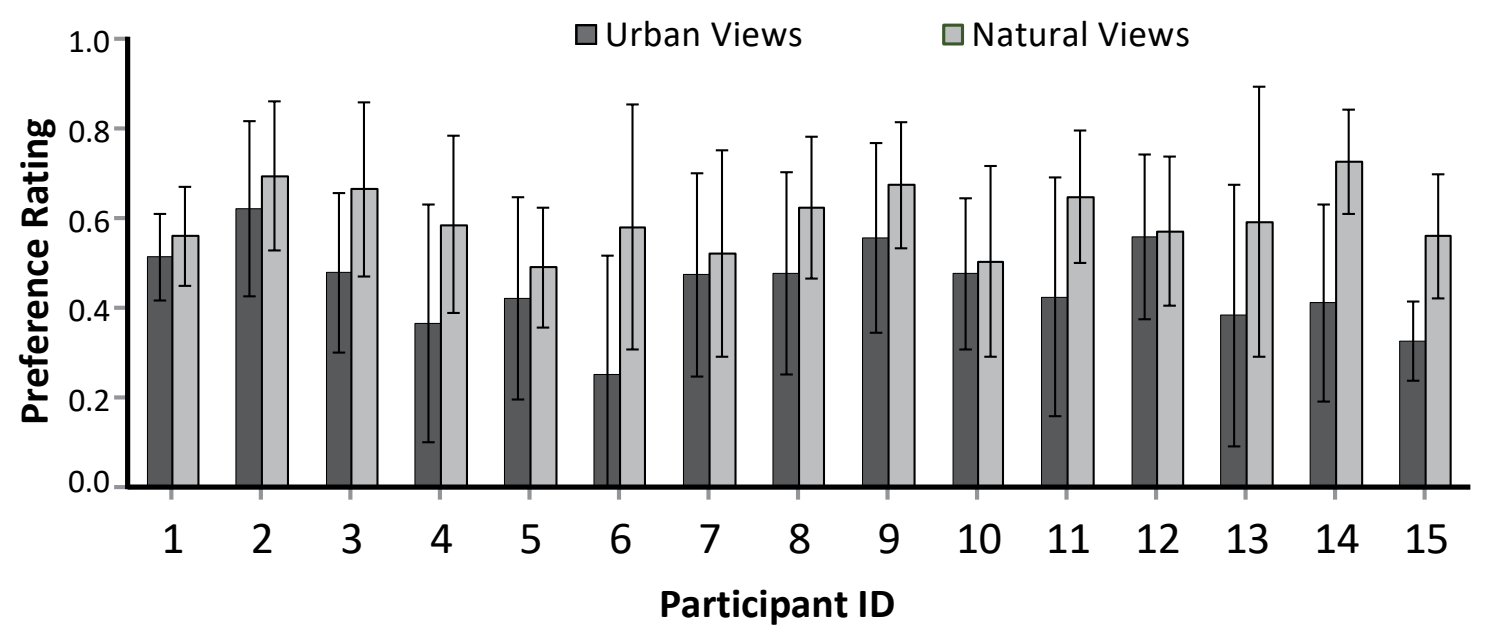

Figure 3 Distribution of preference ratings for urban and natural views. $0=$ Least Preferred, 1 = Most Preferred. Error Bars represent 95\% Confidence Intervals.

\subsubsection{Eye Tracking Measures}

As illustrated in Figure 4, participants' gaze was characterized by a significantly higher number of fixations for urban views $(42.325 \pm 4.785)$ compared to natural $(24.724 \pm$ $6.697)$ views $(\mathrm{t}(14)=9.696, p<0.001, d=2.503)$. The number of saccades was also significantly higher for urban $(44.740 \pm 4.848)$ compared with natural $(35.448 \pm 6.539)$ views $(\mathrm{t}(14)=3.933, p=0.001, d=1.016)$. Conversely, urban views showed significantly lower mean fixation duration $(0.256 \pm 0.045$ seconds $)$ than natural $(0.385 \pm 0.052$ seconds $)$ views $(t(14)=$ 15.496, $p<0.001, d=4.001)$. These results demonstrate that there is a significant and practically relevant difference in gaze behaviour elicited by the two view types. 
a

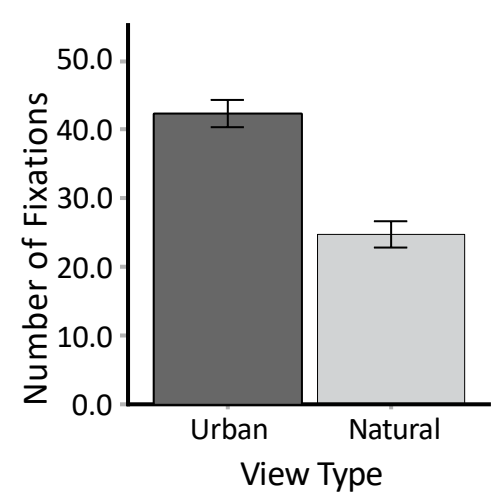

b

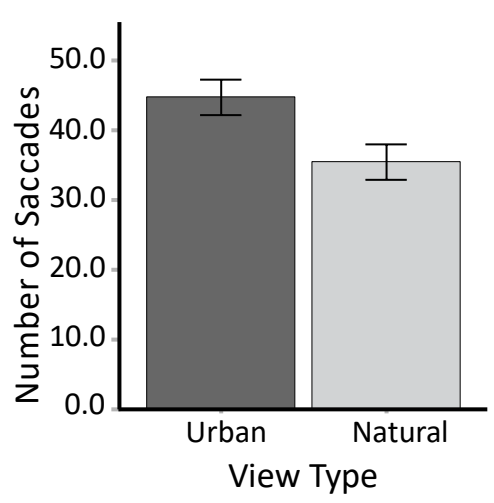

C

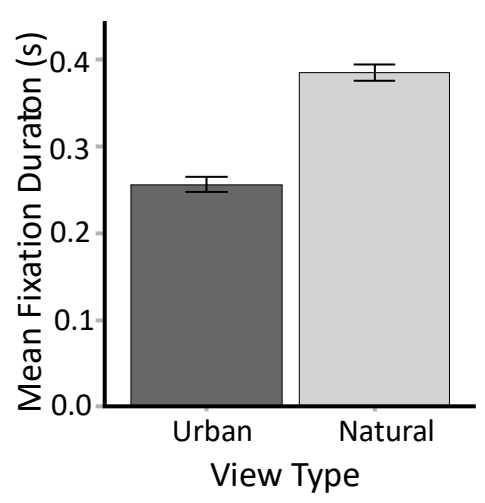

Figure 4 Differences in eye-tracking measures elicited by urban and natural views, $n_{v}=$ 40. $a=$ number of fixations, $b=$ number of saccades, $c=$ mean fixation duration. Error Bars represent +/- 2 SE.

The mean-split method, based on the grand-mean of the group, was used to determine if significant differences in ETMs could be found in the same group of participants $(n=15)$, based on whether - across the full sample of 40 images - the urban views had been previously rated as most preferred $(n=27)$ or least preferred $(n=13)$. Based on the results of ShapiroWilk tests $(p<0.05)$, number of fixations, number of saccades, and mean fixation duration did not fulfil the conditions for normality. A non-parametric Mann-Whitney U test was, therefore, run to detect differences in these ETMs between most and least preferred urban views. The median number of fixations for most preferred (43.800) and least preferred urban views (41.600) was significantly different $(\mathrm{U}=247.000, \mathrm{z}=2.066, p=0.039, r=0.327)$, using an exact sampling distribution for U. Differences in number of saccades were also significant between most preferred $($ median $=46.067)$ and least preferred $($ median $=43.933)$ urban views $(\mathrm{U}=250.000, \mathrm{z}=2.167, p=0.029, r=0.343)$. Conversely, no significant differences in the medians were detected for mean fixation duration between most preferred $($ median $=0.236)$ and least preferred $($ median $=0.248)$ urban views $(\mathrm{U}=111.000, \mathrm{z}=-1.863, p=0.064, r=$ $0.294)$

Similar to the analysis performed for natural views (Section 3.1.2), within-subject (related) t-tests were also conducted for urban scenes to determine whether there was a 
statistically significant difference between ETMs when participants observed 'most preferred' and 'least preferred' views, based on their own preference ratings (Figure 5). The ETMs associated to three out of 40 images of the sample were eliminated from the analysis, since participants had identified the presence of naturalistic features in these views (35). Within the remaining sample of 37 urban images $\left(n_{v}=37\right)$, consistent with the results for natural scenes, most preferred urban views were characterised by a significantly higher number of fixations $(43.728 \pm 4.252)$ as opposed to the least preferred $(42.455 \pm 4.780)$ urban views $(\mathrm{t}(14)=$ 2.214, $p=0.044, r=0.509$ ) (Figure 5a). Similarly, the number of saccades was significantly higher for most preferred $(45.960 \pm 1.141)$ than the least preferred $(44.703 \pm 1.286)$ urban views $(\mathrm{t}(14)=2.207, p=0.045, r=0.508)$ (Figure $5 \mathrm{~b})$. Conversely, no statistically or practically significant difference in mean fixation duration was detected between the least $(0.253 \pm 0.0382 \mathrm{~s})$ and most preferred $(0.252 \pm 0.0481 \mathrm{~s})$ urban views $(\mathrm{t}(14)=0.143, p=0.889$, $r=0.038)$ (Figure 5c).
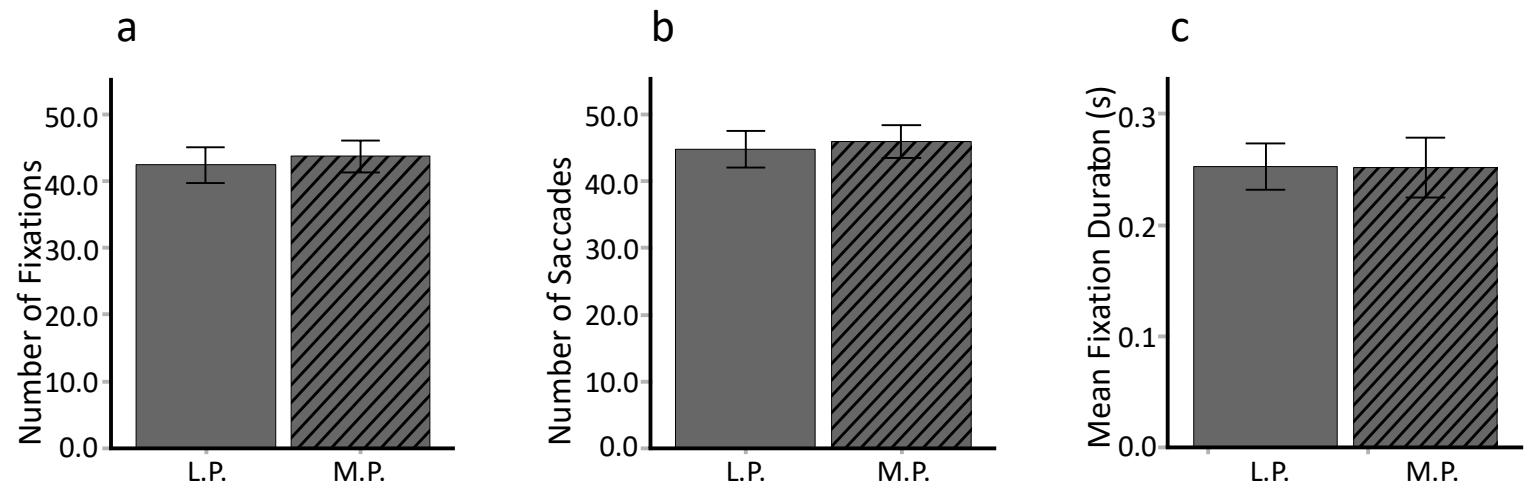

Figure 5 Bar plots comparing eye-tracking measures between most and least preferred urban views, $n_{v}=37, n_{p}=15$. $a=$ Number of fixations, $b=$ Number of saccades, $c=$ Mean fixation duration. LP $=$ Least Preferred Views, MP $=$ Most Preferred Views. Error Bars represent +/- 2 SE. 


\subsection{Personality Traits and Gaze Behaviour in Urban and Natural Views}

Self-reports of nature relatedness (NRS) scores were collected across the two experiments, for urban (NRS $\mathrm{Nuban}_{\text {) }}$ and natural views (NRS $\left.\mathrm{Natural}\right)$. In urban views, the NRS score was inversely related to exploratory gaze behaviour (that is, number of saccades). This was supported by a statistically significant and negative value for the Pearson's productmoment correlation for number of saccades $(r=-0.784, p<0.005)$ (Figure 6), with NRS explaining $61 \%$ of the variance. For the same participants, observing natural views elicited an opposite response in gaze behaviour based on reported NRS scores. Nature relatedness, in fact, was significantly positively correlated with number of saccades $(r=0.615, p=0.015)$, explaining $37.8 \%$ of the variance (Figure 6). The participants who explored natural scenes more (as shown by the higher number of saccades) also had higher NRS scores.

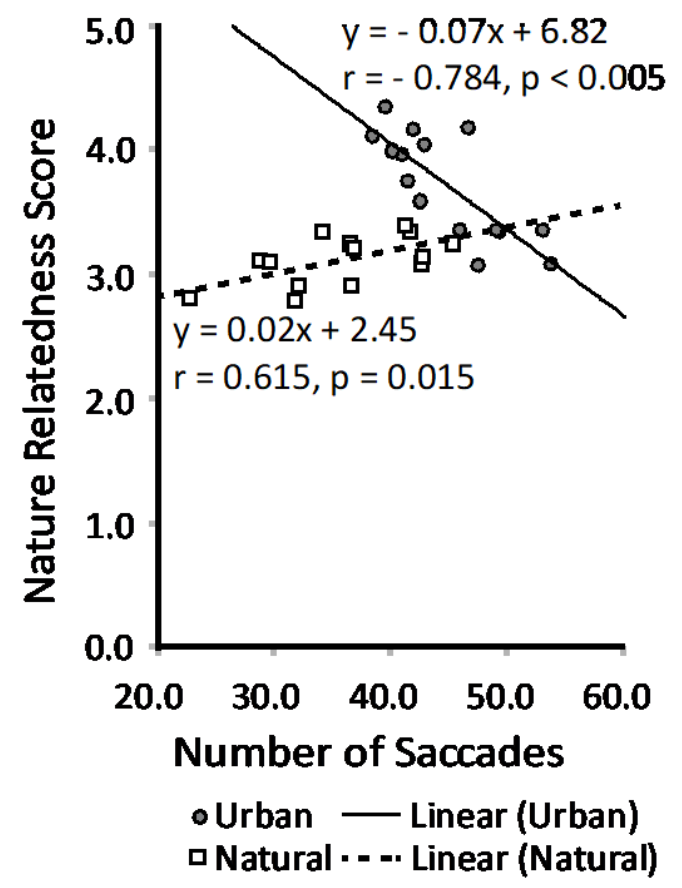

Figure 6 Nature Relatedness Score plotted against number of saccades in urban views (NRSurban) and in natural views (NRSnatural) 


\section{Discussion}

This study used quantitative and qualitative data to investigate gaze correlates of view preference for natural scenes: subjective preference ratings, eye tracking measures, and verbal reasoning. The preference ratings and gaze metrics (ETMs) were then compared to a sub-set of previously collected data on urban views from the same group of participants. The differences in gaze behaviour were also explored with respect to an individual's personality attributes based on perceived connection to nature.

The first finding is related to preferences within natural views. Confirming previous research on the role of higher order perception and meanings associated with the objects in the scene guiding preferences ${ }^{57}$ and restoration, ${ }^{58}$ we found natural elements - e.g., mountains, water, distant views with multiple layers of information, etc. ${ }^{59-61}$ - to be recurrent in most preferred natural views. Participants associated their previous memories and experiences with the scenes, and these modulated their expectations from natural environments, especially when they reminded of "home" or "holiday" locations. ${ }^{14}$ Across the full sample of images, views of seaside, rivers, and ponds were generally appreciated although, as an individual element, the presence of water in itself did not entail higher preference, ${ }^{62}$ being related to other concepts such as care and maintenance ${ }^{59}$ that might change the interpretation. These findings are in line with the ART and SRT theories, which suggest that certain characteristics of views (e.g., water or plants) may lead to feelings of 'being away' (ART) and/or positive affective states (SRT). Views with limited amount of information, or single layers, led to low appreciation, suggesting that preference in natural views might also be mediated by the variety and visible depth of scenes. Long distance natural views have consistently been rated as highly preferred across different studies. ${ }^{4,59,60,63}$

Preference for natural views was also influenced by the presence of people. If the view did not allow further exploration, or presented hazards, it was least preferred. These findings 
are supported by studies suggesting that danger is feared in environments having low level of "prospect" - consistent with Appleton's Prospect-Refuge theory ${ }^{64}$ - this having been found to explain around $30 \%$ of preference variance in forest settings. ${ }^{65}$ This endorses the theory that individuals appraise environments based on how threatening they appear. ${ }^{66,67}$ The notion that preference might be moderated by how other people occupy the view is not new, ${ }^{68}$ especially for studies in urban environments. ${ }^{35,69,70}$ However, in natural landscape preference studies, the presence of people has often been excluded from the stimuli sample. ${ }^{13}$ Our findings create room for re-evaluating landscape preference theories under the lens of human presence, especially with more people today living in cities than in natural settings. ${ }^{70}$

Another interesting aspect of natural view preference is related to the changing patterns and colours in the landscape, where the appreciation for the view of the $\mathrm{sky}^{71}$ and for the variety of trees is associated with the potential they hold for change over time. In previous literature, a preference to see the sky in a window view has been attributed to the knowledge of time of day, weather, and access to daylight with its associated health benefits. ${ }^{72-74}$ The relevance of behavioural changes associated with the dynamics of window views, e.g. natural light ${ }^{75,76}$ and content, ${ }^{71}$ has been emphasised in recent work $^{2,77}$ and could have practical implications on the design of windows to reap the psychological benefits associated with looking towards outdoor views. ${ }^{3,78}$

When searching for differences in preference ratings and associated gaze behaviour (ETMs) across natural and urban scenes, a higher preference was found for natural views as supported by the psych-evolutionary accounts (ART and SRT). We found significantly higher numbers of fixations and saccades, and lower mean fixation durations, when participants looked at urban views compared to natural scenes. ${ }^{29,39,40}$ In a fixed observation time, a higher number of fixations results in lower fixation duration. ${ }^{35}$ Research, in fact, has suggested mean fixation duration as an indicator of perceived naturalness of a landscape. ${ }^{41}$ 
Gaze behaviour is known to reflect the allocation of attention. Any salient feature in views attracts attention and previous work has suggested that there could be an attentional bias for naturalistic elements. ${ }^{79}$ In our previous data collected when the same participants observed urban views, ${ }^{35}$ gaze was more exploratory - that is, higher fixation and saccades - in most preferred than in least preferred views. A higher number of fixations in the same observation time is attributed to an increased capacity to recognise the elements in the image ${ }^{80}$ and more visual scanning. ${ }^{31}$ Since the number of saccades and number of fixations are highly correlated, a higher number of saccades also implies more searching and information gathering. ${ }^{81}$ When participants looked at natural scenes, we did not detect any significant differences in gaze behaviour between most and least preferred views, when the overall grand-mean preference rating derived from the entire group of participants was used as a cutoff value. Yet, some effect sizes bordering practical relevance could be detected. However, when each participant's own preference rating was used to categorise views into their most and least preferred, significant differences in oculomotor responses were found for both natural and urban scenes. This highlights the importance of taking individual differences into account in subjective preferences when analysing gaze patterns. Although it has been common practice in the literature to use a separate panel of participants ${ }^{40}$ to select the visual stimuli $^{39}$ to be used in eye-tracking experiments, ${ }^{82}$ our results suggest that in studies involving the evaluation of complex outdoor scenes, the subjectivity of the content and personal preferences should be taken into account when assessing the factors that drive gaze behaviour. In this context, research has uncovered the role of an individual's nature relatedness in pro-environmental behaviour ${ }^{83}$ and subjective wellbeing. ${ }^{84,85}$ An individual's relatedness to nature is defined as their subjective feeling of being a part of, and in relation to, the natural world. ${ }^{36,86}$ It has been suggested that differences of perception between natural and urban views could be attributed to individual characteristics, such as connection to nature and 
environmental attitudes. ${ }^{21}$ In fact, in this study, we detected an opposite correlation between participants' nature relatedness score (NRS) and the number of saccades when looking at urban and natural views. The detected differences may support the hypothesis that individual predispositions - e.g., a desire to connect with nature ${ }^{10,85}$ - might drive gaze exploration. Indeed, previous studies have suggested that gaze behaviour may reveal personal inclinations and personality traits, ${ }^{43,87,88}$ although the relationship between personal relatedness with nature and appreciation of views requires further research.

In this study, differences in gaze behaviour have been associated to two factors: view type and view preference. Clearly, there could be various constructs at work - namely, naturalness and visual preference evaluation, as found in brain activation studies ${ }^{89}$ suggesting that there might be specific cerebral areas devoted to aesthetic assessment. This may have important practical applications to drive the role, and inform the design, of window views to predict physio-psychological outcomes with building occupants. ${ }^{90}$

\section{Conclusion}

This study investigated subjective and physiological correlates of view preference in urban and natural environments. Subjective preference ratings and eye tracking data were recorded while viewing scenes, with qualitative data adding insights and depth to the inferences from the quantitative analysis. Three main conclusions were drawn.

The first conclusion was that natural views are more preferred than urban views. Preferences of natural views are moderated by different environmental cues - e.g., presence of people, colours, mountains, trees, water, etc. - as suggested by psycho-evolutionary theories such as ART and SRT. Environments perceived as inhospitable or threatening to humans are often least preferred.

Second, it was concluded that gaze behaviour depends on view type and view preference. Participants' gaze behaviour differs significantly based on whether they are 
observing natural or urban scenes. In our sample of participants, observing natural views led to participants' gaze being characterised by lower numbers of fixations and saccades, and longer fixation durations, when compared to urban scenes. This difference in gaze behaviour has been attributed to the restorative potential of natural environments. However, in our study we found similar oculomotor responses when participants observed most preferred natural and urban views. Since neuroscience studies indicate that distinct brain regions are responsible for processing naturalness and aesthetic appraisals, this might suggest that more than one mechanism might be at work during visual scene processing and, therefore, should be accounted for in view assessments.

Third, participants' perceived relationship with nature is related to - and possibly contributes towards - gaze behaviour. Individual scores of nature relatedness were positively correlated with a more exploratory oculomotor response when looking at natural scenes. The opposite gaze behaviour was detected in urban views. This finding might have important implications on how a building occupant may engage with the view out of a window, depending on how they relate with the external natural or urban environment.

Before these findings can be transferred to real-world contexts, it must be acknowledged that our experiments used an eye-tracking device in a controlled laboratory environment, while the participant's head position was secured to a chin and head rest to view a series of pre-selected static stimuli. Although research has shown that participants are reasonably aware of the experience of the space they are viewing, ${ }^{91}$ these settings cannot be fully representative of real-life rooms with windows.

Much research on gaze behaviour and environmental preference has been dedicated to detecting trends in relation to scene properties and types: nature vs. urban views. This study raises questions on individual characteristics that could possibly drive these behaviours and the resultant ocular exploration of views. Further research should investigate the differences 
in perceptions of people who prefer to live and work in natural or urban settings, and how this might drive their view preferences. Studies in urban greening have attributed the role of nature relatedness to subjective wellbeing. However, personal attitudes may still play an important role in the means and extent of engagement with views. With more people spending a large part of their lives in buildings, engagement with the view out of a window is often our only means of connecting with the outdoors. This study contributes a set of new findings that can offer a deeper understanding of the multiple facets of this phenomenon.

\section{Acknowledgements}

The authors would like to thank Dr. Mark Burton and Dr. Chris Scholes for their support in experimental set up and MATLAB Code. We also express our appreciation to the participants for their valuable time.

\section{Declaration of conflicting interest}

The authors declare no potential conflicts of interest with respect to the research, authorship and/or publication of this paper.

\section{Funding}

The authors disclosed receipt of the following financial support for the research, authorship, and/or publication of this article: This work was supported by the University of Nottingham Faculty of Engineering Research Excellence PhD Scholarship awarded to the first author, Scholarship Ref Number: 17226 . This funding source had no role in the design of this study or during its execution, analyses, interpretation of the data or decision to submit results. 


\section{ORCID ID}
Ayesha Batool
0000-0003-0527-4740
Peter Rutherford
0000-0001-9568-6727
Paul McGraw
0000-0001-9484-8560
Timothy Ledgeway 0000-0002-2000-2420
Sergio Altomonte 0000-0002-2518-0234

\section{References}

1. Klepeis NE, Nelson WC, Ott WR, Robinson JP, Tsang AM, Switzer P, et al. The National Human Activity Pattern Survey (NHAPS): A resource for assessing exposure to environmental pollutants. Journal of Exposure Analysis and Environmental Epidemiology 2001; 11: 231-252.

2. Batool A, Rutherford P, McGraw P, Ledgeway T, Altomonte S. Window views: Difference of perception during the COVID-19 lockdown. LEUKOS 2021; 17(4): 380390.

3. Lottrup L, Stigsdotter UK, Meilby H, Claudi AG. The workplace window view: A determinant of office workers' work ability and job satisfaction. Landscape Research 2015; 40(1): 57-75.

4. Tuaycharoen N, Tregenza PR. Discomfort glare from interesting images. Lighting Research and Technology 2005; 37(4): 329-341.

5. Tuaycharoen N, Tregenza PR. View and discomfort glare from windows. Lighting Research and Technology 2007; 39(2): 185-200.

6. Ko WH, Schiavon S, Zhang H, Graham LT, Brager G, Mauss I, Lin YW. The impact of a view from a window on thermal comfort, emotion, and cognitive performance.

Building and Environment 2020. First published 9 March 2020. DOI:

10.1016/j.buildenv.2020.106779

7. Ode Å, Fry G, Tveit MS, Messager P, Miller, D. Indicators of perceived naturalness as drivers of landscape preference. Journal of Environmental Management 2009; 90(1): 375-383.

8. Nelson T, Johnson T, Strong M, Rudakewich G. Perception of Tree Canopy. Journal of Environmental Psychology 2001; 21(3): 315-324.

9. Ulrich RS. Biophilia, Biophobia, and Natural Landscapes. In: Kellert, SK,Wilson EO, (eds) The Biophilia Hypothesis. Washington DC: Island Press, Shearwater Books, 1993.

10. Wilson EO. Biophilia. Cambridge, USA: Harvard University Press, 1984. 
11. Appleton J. The Experience of Landscape. London, UK: John Wiley \& Sons, 1975.

12. Orians GH. Habitat selection: General theory and applications to human behavior. In Lockard JS, (ed) The Evolution of Human Social Behavior. New York: Elsevier North Holland, 1980.

13. Kaplan R and Kaplan S. The Experience of Nature: A Psychological Perspective. New York: Cambridge University Press, 1989.

14. Kaplan S. The restorative benefits of nature: Toward an integrative framework. Journal of Environmental Psychology 1995; 15(3): 169-182.

15. Ulrich RS. Effects of interior design on wellness: theory and recent scientific research. Journal of Health Care Interior Design 1991; 3: 97-109.

16. Joye $\mathrm{Y}$, van den Berg AE. Is love for green in our genes? A critical analysis of evolutionary assumptions in restorative environments research. Urban Forestry \& Urban Greening 2011; 10(4): 261-268.

17. Beute F, de Kort YAW. Thinking of nature: associations with natural versus urban environments and their relation to preference. Landscape Research 2018; 44(4): 374392.

18. Hartig T, Evans GW. Psychological Foundations of Nature Experience. In: Gärling T, Golledge RG (eds.) Behavior and Environment: Psychological and Geographical Approaches. London: North-Holland, 1993, pp. 427-457.

19. Purcell T, Peron E, Berto R. Why do preferences differ between scene types? Environment and Behavior 2001; 33(1): 93-106.

20. van den Berg AE, Koole SL, van der Wulp NY. Environmental preference and restoration: (How) are they related? Journal of Environmental Psychology 2003; 23(2): 135-146.

21. Menardo E, Brondino M, Hall R, Pasini M. Restorativeness in natural and urban environments: A meta-analysis. Psychological Reports 2021; 124(2): 417-437.

22. Peron E, Berto R, Purcell T. Restorativeness, preference and the perceived naturalness of places. Medio Ambiente y Comportamiento Humano 2002; 3(1): 19-34.

23. Han K-T. An exploration of relationships among the responses to natural scenes:Scenic beauty, preference, and restoration. Environment and Behavior 2010; 42(2): 243-270.

24. Meidenbauer KL, Stenfors CUD, Young J, Layden EA, Schertz KE, Kardan O et al. The gradual development of the preference for natural environments. Journal of Environmental Psychology 2019; 65(101328).

25. Hägerhäll CM, Ode Sang Å, Englund J-E, Ahlner F, Rybka K, Huber J, Burenhult N. Do humans really prefer semi-open natural landscapes? A cross-cultural reappraisal. Frontiers in Psychology 2018; 9(822): 1-14. 
26. Buswell GT. How People Look At Pictures: A Study of the Psychology and Perception in Art. Oxford, UK: University of Chicago Press, 1935.

27. Yarbus AL. Eye Movement and Vision. New York, USA: Plenum Press, 1967.

28. Holmqvist K, Nyström M, Andersson R, Dewhurst R, Jarodzka H, van de Weijer J. Eye tracking: A Comprehensive Guide to Methods and Measures. $1^{\text {st }}$ ed. Oxford, UK: Oxford University Press, 2011.

29. Berto R, Massaccesi S, Pasini M. Do eye movements measured across high and low fascination photographs differ? Addressing Kaplan's fascination hypothesis. Journal of Environmental Psychology 2008; 28(2): 185-191.

30. De Lucio JV, Mohamadian M, Ruiz JP, Banayas J, Bernaldez FG. Visual landscape exploration as revealed by eye movement tracking. Landscape and Urban Planning 1996; 34(2): 135-142.

31. Dupont L, Antrop M, Van Eetvelde V. Eye-tracking analysis in landscape perception research: Influence of photograph properties and landscape characteristics. Landscape Research 2014; 39(4): 417-432.

32. Schroeder HW. Does beauty still matter? Experiential and utilitarian values of urban trees, Proceedings of the Urban Trees Research Conference, Birmingham, UK. 13 to 14 April, 2011: pp. 159-165.

33. Stamps III AE. Mystery, complexity, legibility and coherence: A meta-analysis. Journal of Environmental Psychology 2004; 24(1): 1-16.

34. Sonnentag S, Venz L, Casper A. Advances in recovery research: What have we learned? What should be done next? Journal of Occupational Health Psychology 2017; 22(3): 365-380.

35. Batool A, Rutherford P, McGraw P, Ledgeway T, Altomonte S. View preference in urban environments. Lighting Research and Technology. First published 29 December 2020. DOI: 1477153520981572.

36. Nisbet EK, Zelenski JM, Murphy SA. The nature relatedness scale: Linking individuals' connection with nature to environmental concern and behavior. Environment and Behavior 2009; 41(5): 715-740.

37. Orquin JL, Mueller-Loose S. Attention and choice: A review on eye movements in decision making. Acta Psychologica 2013; 144(1): 190-206.

38. Khanie Sarey M, Stoll J, Mende S, Wienold J, Einhäuser W, Andersen M. Investigation of gaze patterns in daylit workplaces: using eye-tracking methods to objectify view direction as a function of lighting conditions, Proceedings of the CIE Centenary Conference "Towards a New Century of Light", Vienna, Austria. 2013: pp.250-259.

39. Valtchanov D and Ellard CG. Cognitive and affective responses to natural scenes: Effects of low level visual properties on preference, cognitive load and eye-movements. Journal of Environmental Psychology 2015; 43: 184-195. 
40. Franěk M, Šefara D, Petružálek J, Cabal J, Myška, K. Differences in eye movements while viewing images with various levels of restorativeness. Journal of Environmental Psychology 2018; 57: 10-16.

41. Cottet M, Vaudor L, Tronchère H, Roux-Michollet D, Augendre M, Brault V. Using gaze behavior to gain insights into the impacts of naturalness on city dwellers' perceptions and valuation of a landscape. Journal of Environmental Psychology 2018; 60: 9-20.

42. Kim M, Kang Y, and Abu Bakar S. A Nightscape Preference Study using Eye Movement Analysis. Alam Cipta 2013; 6(2): 85-99.

43. Kaspar K, König P. Overt attention and context factors: The impact of repeated presentations, image type, and individual motivation. PLOS ONE 2011; 6: e21719.

44. Onat S, Açık A, Schumann F, König P. The contributions of image content and behavioral relevancy to overt attention. PLOS ONE 2014; 9: e93254.

45. Amundadottir ML, Rockcastle S, Sarey Khanie M, Andersen M. A human-centric approach to assess daylight in buildings for non-visual health potential, visual interest and gaze behavior. Building and Environment 2017; 113: 5-21.

46. Olmos A and Kingdom FAA. A biologically inspired algorithm for the recovery of shading and reflectance images. Perception 2004; 33(12): 1463-1473.

47. Peirce JW. PsychoPy-Psychophysics software in Python. Journal of Neuroscience Methods 2007; 162(1-2): 8-13.

48. Field A, Hole G. How to Design and Report Experiments. London, UK: SAGE Publications Ltd., 2003.

49. The MathWorks Inc. MATLAB and Statistics Toolbox Release R2017a, Available online at https://uk.mathworks.com/products/matlab.html 2017.

50. Andersson R, Larsson L, Holmqvist K, Stridh M, Nyström, M. One algorithm to rule them all? An evaluation and discussion of ten eye movement event-detection algorithms. Behavior Research Methods 2017; 49(2): 616-637.

51. Nyström M, Holmqvist K. An adaptive algorithm for fixation, saccade, and glissade detection in eyetracking data. Behavior Research Methods 2010; 42(1): 188-204.

52. Field A. Discovering Statistics Using SPSS. $3^{\text {rd }}$ ed. London, UK: SAGE Publications Ltd., 2009.

53. Cohen J. Statistical Power Analysis For The Behavioral Sciences. $2^{\text {nd }}$ ed. Hillsdale, N.J.: Lawrence Erlbaum Associates, 1988.

54. Rosenthal R. Meta-Analytic Procedures for Social Research. Newbury Park, California, USA: SAGE Publications Inc., 1991.

55. Brown W. Some experimental results in the correlation of mental abilities. British Journal of Psychology, 1904-1920 1910; 3(3): 296-322. 
56. Spearman C. Correlation Calculated from Faulty Data. British Journal of Psychology, 1904-1920 1910; 3(3): 271-295.

57. Henderson JM, Hayes TR. Meaning-based guidance of attention in scenes as revealed by meaning maps. Nature Human Behaviour 2017; 1(10): 743-747.

58. Menzel C, Reese G. Seeing nature from low to high levels: mechanisms underlying the restorative effects of viewing nature images. PsyArXiv. Epub ahead of print 5 March 2021. DOI: $10.31234 /$ osf.io/e32vb.

59. Hellinga H. Daylight and View - The Influence of Windows on the Visual Quality of Indoor Spaces. PhD Dissertation, Technische Universiteit Delft, the Netherlands, 2013.

60. Markus TA. The function of windows - A reappraisal. Building Science 1967; 2(2): $97-$ 121.

61. CEN/TC 169. European Standard EN 17037: Daylight in Buildings 2018; European Committee for Standardization, Hørsholm, Denmark.

62. Purcell AT, Lamb RJ, Mainardi Peron E, Falchero, S. Preference or preferences for landscape? Journal of Environmental Psychology 1994; 14(3): 185-209.

63. Matusiak BS, Klöckner CA. How we evaluate the view out through the window. Architectural Science Review 2016; 59(3): 203-211.

64. Gatersleben B, Andrews M. When walking in nature is not restorative-The role of prospect and refuge. Health \& Place 2013; 20: 91-101.

65. Herzog TR, Kutzli GE. Preference and perceived danger in field/forest settings. Environment and Behavior 2002; 34(6): 819-835.

66. Lazarus RS, Launier R. Stress-Related Transactions between Person and Environment. In: Pervin LA and Lewis M (eds) Perspectives in Interactional Psychology. Boston, MA: Springer US, 1978, pp. 287-327.

67. Brosschot JF, Verkuil B, Thayer JF. Generalized Unsafety Theory of Stress: Unsafe Environments and Conditions, and the Default Stress Response. International Journal of Environmental Research and Public Health 2018; 15(3): 464.

68. Nordh H, Alalouch C, Hartig T. Assessing restorative components of small urban parks using conjoint methodology. Urban Forestry \& Urban Greening 2011; 10(2): 95-103.

69. Twedt E, Rainey RM, Proffitt DR. Beyond nature: The roles of visual appeal and individual differences in perceived restorative potential. Journal of Environmental Psychology 2019; 65: 101322.

70. Whyte WH. The Social Life of Small Urban Spaces. Washington, D.C.: Conservation Foundation, 1980.

71. Masoudinejad S, Hartig T. Window view to the sky as a restorative resource for residents in densely populated cities. Environment and Behavior 2020; 52(4): 401-436. 
72. Hansen EK, Bjørner T, Xylakis E, et al. An experiment of double dynamic lighting in an office responding to sky and daylight: Perceived effects on comfort, atmosphere and work engagement. Indoor and Built Environment. First Published 16 February, 2021. DOI: $10.1177 / 1420326 x 21991198$.

73. Veitch JA, Galasiu AD. The Physiological and Psychological Effects of Windows, Daylight, and View at Home: Review and Research Agenda. Research Report: National Research Council Canada Institute for Research in Construction, 28 February, 2012

74. Heschong L. Visual Delight in Architecture. New York: Routledge, 2021.

75. Rodriguez F, Garcia-Hansen V, Allan A, Isoardi, G. Subjective responses toward daylight changes in window views: Assessing dynamic environmental attributes in an immersive experiment. Building and Environment. First published 23 February 2021. DOI: 10.1016/j.buildenv.2021.107720

76. Kompier ME, Smolders KCHJ, de Kort YAW. A systematic literature review on the rationale for and effects of dynamic light scenarios. Building and Environment. First published 25 September 2020. DOI: 10.1016/j.buildenv.2020.107326.

77. Webler FS, Spitschan M, Foster RG, Andersen M, Peirson SN. What is the 'spectral diet' of humans? Current Opinion in Behavioral Sciences 2019; 30: 80-86.

78. Vásquez NG, Felippe ML, Pereira FOR, Kuhnen A. Luminous and visual preferences of young children in their classrooms: Curtain use, artificial lighting and window views. Building and Environment 2019; 152: 59-73.

79. Joye Y, Pals R, Steg L, Evans BL. New methods for assessing the fascinating nature of nature experiences. PLOS ONE 2013; 8(7): e65332.

80. Duchowski AT. Eye Tracking Methodology: Theory and Practice. $3^{\text {rd }}$ ed. Cham, Switzerland: Springer, 2017.

81. Goldberg JH, Kotval XP. Computer interface evaluation using eye movements: methods and constructs. International Journal of Industrial Ergonomics 1999; 24(6): 631-645.

82. Dupont L, Antrop M, Van Eetvelde V. Does landscape related expertise influence the visual perception of landscape photographs? Implications for participatory landscape planning and management. Landscape and Urban Planning 2015; 141: 68-77.

83. Mackay CML, Schmitt MT. Do people who feel connected to nature do more to protect it? A meta-analysis. Journal of Environmental Psychology 2019; 65(101323).

84. Zelenski JM, Nisbet EK. Happiness and Feeling Connected:The Distinct Role of Nature Relatedness. Environment and Behavior 2014; 46(1): 3-23.

85. Nisbet EK, Zelenski JM. Underestimating Nearby Nature:Affective Forecasting Errors Obscure the Happy Path to Sustainability. Psychological Science 2011; 22(9): 11011106. 
86. Mayer FS, Frantz CM. The connectedness to nature scale: A measure of individuals' feeling in community with nature. Journal of Environmental Psychology 2004; 24(4): 503-515.

87. Maran T, Moder S, Furtner M, Ravet-Brown T, Liegl S. From self-report to behavior: Mapping charisma onto naturalistic gaze patterns. Personality and Individual Differences 2020; 152(109562).

88. Rauthmann JF, Seubert CT, Sachse P, Furtner MR. Eyes as windows to the soul: Gazing behavior is related to personality. Journal of Research in Personality 2012; 46(2): 147-156.

89. Jacobs RHAH, Renken R, Cornelissen FW. Neural Correlates of Visual Aesthetics Beauty as the Coalescence of Stimulus and Internal State. PLOS ONE 2012; 7(2): e31248.

90. Aries MBC, Veitch JA, Newsham GR. Windows, view, and office characteristics predict physical and psychological discomfort. Journal of Environmental Psychology 2010; 30(4): 533-541.

91. Hollander JB, Purdy A, Wiley A, Foster V, Jacob RJK, Taylor HA, Brunyé TT. Seeing the city: using eye-tracking technology to explore cognitive responses to the built environment. Journal of Urbanism 2018; 12(2): 156-171. 


\section{Tables}

Table 1 Subjective preference ratings for all images.

P.R.Mean = Mean Preference Rating, S.D. $=$ Standard Deviation, $C I=$ Confidence Interval

\begin{tabular}{lll}
\hline Image & P.R.Mean & S.D. $\left[\mathbf{C I}_{\mathbf{m i n}}-\mathbf{C I}_{\mathbf{m a x}}\right]$ \\
$\mathbf{\text { ID }}$ & & \\
\hline $\mathbf{i 1}$ & 0.565 & $0.192[0.468,0.663]$ \\
$\mathbf{i 2}$ & 0.567 & $0.248[0.468,0.663]$ \\
$\mathbf{i 3}$ & 0.612 & $0.136[0.547,0.677]$ \\
$\mathbf{i 4}$ & 0.705 & $0.209[0.600,0.811]$ \\
$\mathbf{i 5}$ & 0.363 & $0.200[0.262,0.464]$ \\
$\mathbf{i 6}$ & 0.704 & $0.192[0.607,0.801]$ \\
$\mathbf{i 7}$ & 0.632 & $0.230[0.515,0.749]$ \\
$\mathbf{i 8}$ & 0.650 & $0.153[0.573,0.727]$ \\
$\mathbf{i 9}$ & 0.501 & $0.190[0.450,0.598]$ \\
$\mathbf{i 1 0}$ & 0.586 & $0.147[0.511,0.661]$ \\
$\mathbf{i 1 1}$ & 0.585 & $0.157[0.506,0.665]$ \\
$\mathbf{i 1 2}$ & 0.646 & $0.184[0.553,0.739]$ \\
$\mathbf{i 1 3}$ & 0.682 & $0.128[0.617,0.747]$ \\
$\mathbf{i 1 4}$ & 0.688 & $0.133[0.621,0.755]$ \\
$\mathbf{i 1 5}$ & 0.584 & $0.133[0.621,0.755]$ \\
$\mathbf{i 1 6}$ & 0.655 & $0.223[0.543,0.768]$ \\
$\mathbf{i 1 7}$ & 0.477 & $0.209[0.372,0.583]$ \\
$\mathbf{i 1 8}$ & 0.675 & $0.168[0.590,0.760]$ \\
$\mathbf{i 1 9}$ & 0.504 & $0.171[0.418,0.590]$ \\
$\mathbf{i 2 0}$ & 0.653 & $0.139[0.583,0.723]$ \\
$\mathbf{i 2 1}$ & 0.721 & $0.157[0.641,0.800]$ \\
$\mathbf{i 2 2}$ & 0.679 & $0.144[0.606,0.751]$ \\
$\mathbf{i 2 3}$ & 0.558 & $0.216[0.449,0.667]$ \\
$\mathbf{i 2 4}$ & 0.667 & $0.191[0.571,0.764]$ \\
$\mathbf{i 2 5}$ & 0.481 & $0.227[0.367,0.596]$ \\
$\mathbf{i 2 6}$ & 0.435 & $0.234[0.317,0.554]$ \\
$\mathbf{i 2 7}$ & 0.510 & $0.228[0.394,0.626]$ \\
$\mathbf{i 2 8}$ & 0.668 & $0.129[0.603,0.733]$ \\
$\mathbf{i 2 9}$ & 0.681 & $0.161[0.599,0.749]$ \\
$\mathbf{i 3 0}$ & 0.624 & $0.173[0.537,0.711]$ \\
$\mathbf{i 3 1}$ & 0.677 & $0.142[0.605,0.749]$ \\
$\mathbf{i 3 2}$ & 0.681 & $0.148[0.606,0.756]$ \\
$\mathbf{i 3 3}$ & 0.719 & $0.157[0.511,0.669]$ \\
$\mathbf{i 3 4}$ & 0.590 & $0.157[0.511,0.669]$ \\
$\mathbf{i 3 5}$ & 0.527 & $0.285[0.383,0.671]$ \\
$\mathbf{i 3 6}$ & 0.588 & $0.151[0.512,0.664]$ \\
$\mathbf{i 3 7}$ & 0.501 & $0.186[0.407,0.595]$ \\
$\mathbf{i 3 8}$ & 0.465 & $0.210[0.359,0.572]$ \\
$\mathbf{i 3 9}$ & 0.551 & $0.199[0.451,0.652]$ \\
$\mathbf{i 4 0}$ & 0.580 & $0.169[0.495,0.665]$ \\
\hline & &
\end{tabular}


Table 2 Frequencies of selection of the three most and the three least preferred views in the preference rating task and pile sorting task

\begin{tabular}{llll}
\hline & Image ID & $\begin{array}{l}\text { Preference Rating } \\
\text { Task (N) }\end{array}$ & Pile Sorting Task (N) \\
\hline Most Preferred Views & i4 & 6 & 3 \\
& i33 & 3 & 5 \\
& i6 & 4 & 2 \\
Least Preferred Views & i5 & 7 & 9 \\
& i35 & 4 & 4 \\
& i27 & 4 & 3 \\
\hline
\end{tabular}


Table 3 Frequencies of words associated with most and least preferred views (ordered alphabetically)

\begin{tabular}{lll}
\hline Word & $\begin{array}{l}\text { Frequency of words in most } \\
\text { preferred views }\end{array}$ & $\begin{array}{l}\text { Frequency of words in least } \\
\text { preferred views }\end{array}$ \\
\hline Colour & 13 & 5 \\
Mountain/Hill & 12 & 2 \\
Natural & 10 & 8 \\
People/Human & 14 & 9 \\
Sky & 7 & 1 \\
Tree & 11 & 7 \\
Water & 10 & 7 \\
\hline
\end{tabular}


Table 4 Descriptors for most and least preferred views (ordered alphabetically)

\begin{tabular}{lll}
\hline & Descriptor Words & Frequency (N) \\
\hline Most Preferred Views & Changing & 6 \\
& Holiday & 5 \\
& Home & 5 \\
Least Preferred Views & Peaceful & 8 \\
& Barren & 6 \\
& Can't & 10 \\
& Difficult & 6 \\
& Inhospitable & 4 \\
\hline
\end{tabular}




\section{List of Figures}

Figure 1 Most frequently selected (A) 'most preferred' and (B) 'least preferred' natural views and their heatmaps. Normalised fixation frequency is the total number of times that a pixel was viewed in the image, divided by the total number of valid eye-tracker samples for the duration of the image presentation, 15s (after removing blinds). Image size is $1024 \mathrm{x} 768$ pixels.

Figure 2 Gaze behaviour measures for most preferred and least preferred natural views, for all participants $\left(n_{p}=15\right)$ and all views in the sample $\left(n_{v}=40\right) . a=$ Number of fixations, $b=$ Number of saccades, $\mathrm{c}=$ Mean Fixation Duration. $\mathrm{LP}=$ Least Preferred Views, MP $=$ Most Preferred Views. Error Bars represent +/- 2 SE.

Figure 3 Distribution of preference ratings for urban and natural views. $0=$ Least Preferred, 1 $=$ Most Preferred. Error Bars represent 95\% Confidence Intervals.

Figure 4 Differences in eye-tracking measures elicited by urban and natural views, $\mathrm{n}_{\mathrm{v}}=40 . \mathrm{a}=$ number of fixations, $\mathrm{b}=$ number of saccades, $\mathrm{c}=$ mean fixation duration. Error Bars represent +/- 2 SE.

Figure 5 Bar plots comparing eye-tracking measures between most and least preferred urban views, $\mathrm{n}_{\mathrm{v}}=37, \mathrm{n}_{\mathrm{p}}=15 . \mathrm{a}=$ Number of fixations, $\mathrm{b}=$ Number of saccades, $\mathrm{c}=$ Mean fixation duration. $\mathrm{LP}=$ Least Preferred Views, MP $=$ Most Preferred Views. Error Bars represent $+/-2$ SE.

Figure 6 Nature Relatedness Score plotted against number of saccades in urban views $\left(\mathrm{NRS}_{\text {urban }}\right)$ and in natural views $\left(\mathrm{NRS}_{\text {natural }}\right)$ 